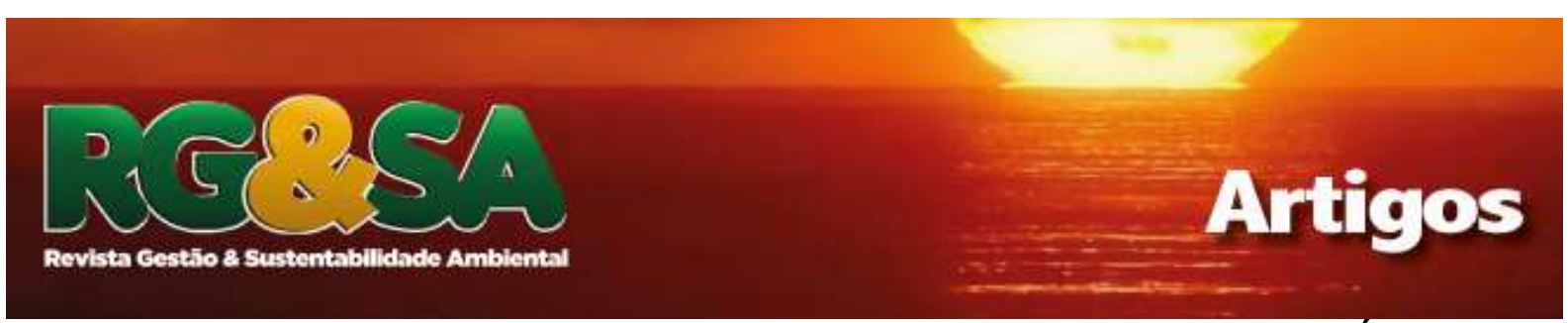

\title{
EFEITO DE BIOFERTILIZANTE NO CRESCIMENTO DE ALFACE, RÚCULA, TOMATE, CEBOLINHA E REPOLHO.
}

DOI: $10.19177 /$ rgsa.v8e32019278-287

\author{
Carlos Fernando de Andrade e Silva ${ }^{1}$ \\ Anderson Oliveira Lattini ${ }^{2}$ \\ Renata Carolina Zanetti Lofrano ${ }^{3}$
}

\begin{abstract}
RESUMO
O objetivo do trabalho foi avaliar o efeito do uso de biofertilizante sobre o desenvolvimento em altura de hortaliças. $O$ desenvolvimento das hortaliças alface, cebolinha, tomate, rúcula e repolho foi acompanhado, desde o cultivo de mudas até os 50 dias, mediante a aplicação de um biofertilizante, cedido por empresa local e com composição em nutrientes conhecida. Para todas as hortaliças, o crescimento medido diretamente pela altura das plantas, foi superior após as aplicações do biofertilizante. Considerando a possibilidade de uso de produtos locais nas propriedades agrícolas para composição de biofertilizantes, o atual trabalho reforça a importância do seu uso para a sustentabilidade agrícola.
\end{abstract}

Palavras-chave: Fertilizante Orgânico. Hortaliças. Cultivo Agroecológico. Sustentabilidade.

\footnotetext{
1 Universidade Federal de São João Del-Rei/UFSJ. E-mail: carlos.anseg@gmail.com

2 Universidade Federal de São João Del-Rei/UFSJ. Departamento de Ciências Exatas e Biológicas/DECEB. E-mail: aolatini@ufsj.edu.br

3 Universidade Federal de São João del-Rei/UFSJ. Departamento de Engenharia Química/DEQUI. Email: renataczlofrano@ufsj.edu.br
} 


\title{
BIOFERTILIZER EFFECT ON LETTUCE, ONION, TOMATO, RUCULA AND CABBAGE GROWTH.
}

\begin{abstract}
The objective of this work was to evaluate the effect of the use of a biofertilizer on the height development of vegetables. The development of the lettuce, chives, tomato, arugula and cabbage vegetables was measured from the cultivation of seedlings until the 50 days, through the application of a biofertilizer, provided by a local company and with a known nutrient composition. For all vegetables, the growth measured directly by the height of the plants, was superior after the applications of the biofertilizer. Considering the possibility of using local products in the agricultural properties for the composition of biofertilizers, the current work reinforces the importance of its use for agricultural sustainability.
\end{abstract}

Keywords: Organic Fertilizer. Vegetables. Agroecological Cultivation. Sustainability.

\section{INTRODUÇÃO}

A exploração intensiva do solo com culturas de crescimento rápido e de elevado rendimento, somada às características genéticas e fisiológicas das espécies cultivadas de alta exigência em nutrientes, predispõe o solo a consideráveis perdas de matéria orgânica e de nutrientes (HERNANI et al., 1999; KASCHUK et al., 2011). Estas perdas têm justificado a aplicação de grande quantidade de fertilizantes químicos, que atendem à exigência em nutrientes, mas, que podem induzir fitotoxidez, salinização dos solos, acúmulo de nitrato nos tecidos das plantas e oneração demasiada da produção (MEDEIROS et al., 2007; NOVOTNY, 2011).

Como alternativas às práticas convencionais, práticas de manejo que priorizam a manutenção do carbono orgânico no solo, como o plantio direto, usam de adubos verdes e redução do uso de implementos agrícolas, são opções cada vez mais comuns entre os agricultores (CARVALHO et al., 2010; LOUREIRO et al., 2016). O uso de biofertilizantes é uma destas práticas que têm se tornado cada vez mais frequente, devido aos baixos custos de sua obtenção, melhoras na qualidade das plantas e da estrutura física do solo, otimização da na ciclagem de nutrientes e devido às melhoras ambientais nos sistemas de cultivo (CAVALCANTE et al., 2010; SOARES et al., 2014). Os biofertilizantes podem ser obtidos com o uso de subprodutos do próprio agroecossistema, como dejetos de animais, cinzas e folhas 
que são processados a partir da digestão anaeróbica ou aeróbica tornando-se eficientes fontes de nutrientes às plantas cultivadas (KIEHL, 2010).

De acordo com a Lei $n^{0} 6.894$, de 16 de dezembro de 1980; decreto $n^{0} 4.954$, de 14 de janeiro de 2004; capítulo I; artigo $2^{0}$, Biofertilizante é definido como "produto que contém princípio ativo ou agente orgânico, isento de substâncias agrotóxicas, capaz de atuar, direta ou indiretamente, sobre o todo ou parte das plantas cultivadas, elevando a sua produtividade, sem ter em conta o seu valor hormonal ou estimulante" (BRASIL, 2004). Apesar da sua variável composição química, comumente os biofertilizantes apresentam a maioria dos nutrientes necessários às espécies vegetais, além de microrganismos, responsáveis pela decomposição da matéria orgânica, que resulta na produção de gás e liberação de metabólicos (BETTIOL, 2009). Usados em baixa dosagem e diluídos em água, podem ser aplicados como adubo foliar, em sementes, e no solo suprindo deficiências nutricionais e melhorando biológica, química e fisicamente a qualidade do solo (KIEHL, 2010).

Com o intuito de analisarmos uma técnica capaz de boa reposição dos níveis de fertilidade do solo e ao mesmo tempo, constituir modo ambientalmente responsável de cultivo, testamos aqui os efeitos de um biofertilizante sobre o crescimento das hortaliças alface, rúcula, tomate, cebolinha e repolho.

\section{MATERIAIS E MÉTODOS}

O estudo foi desenvolvido no município de Ouro Branco/MG, onde o clima é do tipo Cwb na classificação de Köppen, apresentando inverno seco e verão temperado, com pluviosidade média anual de $1188 \mathrm{~mm}$ e temperatura média anual de $20,7^{\circ} \mathrm{C}$. Na região, a cobertura vegetal caracteriza-se por transição entre Cerrado e Mata Atlântica, ocorrendo campos rupestres nas maiores altitudes.

Para se estudar o efeito de um biofertilizante sobre o crescimento de rúcula, repolho, tomate, alface e cebolinha, foram planejados experimentos de 50 dias, entre dezembro e janeiro, conduzidos em estufa fechada, com proteção de tela de galinheiro e plástico. Na estufa, bandejas com capacidade para 180 mudas foram preparadas com o mesmo substrato para as cinco culturas. Passados 30 dias da germinação e procedimento de desbaste, 10 mudas de cada uma das espécies estudadas foram transferidas e replantadas em vasos $(9 \mathrm{~cm}$ de altura $\mathrm{x} 12,5 \mathrm{~cm}$ 
diâmetro de abertura) contendo o mesmo substrato. Com o auxílio de um sistema de irrigação automático tipo leque, com angulação de 110 graus, os cultivares foram molhados durante um minuto, a cada hora, das 7:30 h às 16:30 h. Em dias chuvosos o número de irrigações foi reduzido pela metade.

O biofertilizante utilizado (Cresce Fácil) foi cedido por uma empresa da região e produzido pelo processo de compostagem, utilizando-se húmus junto de cinzas, esterco de boi, farinha de osso orgânica, leite, rapadura, raízes, folhas e frutos, obtendo-se uma composição quimicamente determinada (Tabela 1). Uma solução contendo $1 \mathrm{~L}$ de biofertilizante diluído em $10 \mathrm{~L}$ de água foi produzida para a adubação das plantas experimentais. No tratamento experimental foi realizada a adição semanal de $20 \mathrm{~mL}$ da solução de biofertilizante preparada, perfazendo um total de 6 aplicações no decorrer dos 50 dias de experimento, sendo 3 enquanto mudas e 3 após o transplante para os vasos. O tratamento controle recebeu $20 \mathrm{~mL}$ de água no lugar do biofertilizante. Também semanalmente, foi tomada a altura $(\mathrm{mm})$ de todas as réplicas das cinco culturas estudadas, rúcula, repolho, tomate, alface e cebolinha, nos dois tratamentos.

Utilizou-se um delineamento experimental inteiramente casualizado, com 5 repetições e 2 tratamentos que representaram a presença ou não do biofertilizante estudado para cada uma das hortaliças. Como as aferições ocorreram nos mesmos indivíduos ao longo do tempo, para cada espécie de hortaliça foi usada uma ANOVA com medidas repetidas no tempo, que considerou tal dependência. Assim, foi utilizada a variável dependente altura (quantitativa contínua) e as variáveis independentes "biofertilizante" (com resposta categórica binária, "sim" ou "não") e aferição (4 diferentes tempos após a transposição das mudas). O nível de significância utilizado foi de $5 \%$. 
Tabela 1 - Descrição da composição química do biofertilizante (Cresce Fácil) utilizado neste estudo.

\begin{tabular}{cc}
\hline Composição & Valores em \% \\
\hline Fósforo $\left(\mathrm{P}_{2} \mathrm{O}_{5}\right)$ & 0,044 \\
\hline Cálcio $(\mathrm{Ca})$ & 0,077 \\
\hline Carbono orgânico & 3,580 \\
\hline Enxofre $(\mathrm{S})$ & 0,061 \\
\hline Ferro $(\mathrm{Fe})$ & 0,046 \\
\hline Magnésio $(\mathrm{Mg})$ & 0,045 \\
\hline Manganês $(\mathrm{Mn})$ & 0,003 \\
\hline Nitrogênio & 0,050 \\
\hline Zinco $(\mathrm{Zn})$ & 0,026 \\
\hline Cobalto $(\mathrm{Co})$ & $<0,0001$ \\
\hline Cobre $(\mathrm{Cu})$ & $<0,0001$ \\
\hline Boro $(\mathrm{B})$ & 0,021 \\
\hline Cloro $(\mathrm{Cl})$ & 0,038 \\
\hline Molibdênio $(\mathrm{Mo})$ & $<0,001$ \\
\hline pH & 4,8 \\
\hline
\end{tabular}

\section{RESULTADOS E DISCUSSÃO}

Além da função nutricional, os biofertilizantes têm alta atividade microbiana na decomposição de seus componentes, liberando nutrientes que irão contribuir no desenvolvimento da planta e na transferência contínua de nutrientes do solo para a planta e da planta para o solo (KIEHL, 1993; RIBEIRO, 2011). Isto pode explicar a resposta unânime de aumento na altura que foi obtida para todas as cinco hortaliças utilizadas no experimento (Tabela 2).

Apesar de todas as cinco culturas terem apresentado um aumento significativo em altura na data de colheita, este aumento foi mais expressivo nas plantas de alface, onde as que tiveram acesso ao biofertilizante foram, em média, $70 \%$ mais altas (Figura 1A). Essa hortaliça foi a que sofreu o maior efeito do uso do biofertilizante em seu crescimento, principalmente se analisarmos as diferenças de alturas obtidas com e sem biofertilizantes nas aferições 3 e 4 . Para as outras hortaliças a diferença na colheita foi em torno de $20 \%$ para tomate, rúcula e repolho e de $10 \%$ para a cebolinha. 
Tabela 2 - Apresentação dos resultados das análises para homogeneidade de altura para as hortaliças alface, tomate, repolho, cebolinha e rúcula, em função dos fatores "biofertilizante", "tempo" e a interação entre os dois. Valores de p em negrito indicam relações significativas.

\begin{tabular}{lcccccc}
\hline \multirow{2}{*}{ Cultura } & \multicolumn{2}{c}{ Biofertilizante } & \multicolumn{2}{c}{ Tempo } & \multicolumn{2}{c}{ Biofertilizante x Tempo } \\
\cline { 2 - 7 } & $\mathrm{F}$ & $\mathrm{P}$ & $\mathrm{F}$ & $\mathrm{P}$ & $\mathrm{F}$ & $\mathrm{p}$ \\
\hline Alface & 30,480 & $<\mathbf{0 , 0 0 1}$ & 1411,328 & $<\mathbf{0 , 0 0 1}$ & 17,091 & $<\mathbf{0 , 0 0 1}$ \\
\hline Tomate & 47,427 & $<\mathbf{0 , 0 0 1}$ & 241,485 & $<\mathbf{0 , 0 0 1}$ & 9,909 & $<\mathbf{0 , 0 0 1}$ \\
\hline Repolho & 17,933 & $\mathbf{0 , 0 0 2}$ & 82,170 & $<\mathbf{0 , 0 0 1}$ & 0,300 & 0,825 \\
\hline Cebolinha & 7,569 & $\mathbf{0 , 0 2 5}$ & 128,074 & $<\mathbf{0 , 0 0 1}$ & 0,345 & 0,792 \\
\hline Rúcula & 20,672 & $\mathbf{0 , 0 0 1}$ & 84,121 & $<\mathbf{0 , 0 0 1}$ & 0,259 & 0,854 \\
\hline
\end{tabular}

Os biofertilizantes apresentam, comumente, concentrações de substâncias húmicas maiores do que a maior parte dos solos disponíveis no país, já que são obtidos de fontes mais ricas nestas substâncias (ZANDONADI et al., 2014). Aliado a isso, as quantidades satisfatórias de Magnésio, Cálcio, Enxofre, Boro, Molibdênio e Zinco (Tabela 1) devem explicar o maior crescimento do tomate e do repolho e cebolinha, que tiveram as suas exigências nutricionais de Boro e Molibdênio atendidas. Apesar do maior crescimento com o uso do biofertilizante, alface e rúcula, que necessitam de dosagem razoável de Boro e Cobre (ADAMS et al., 1986; GRANGEIRO et al., 2003; YURI et al., 2004) foram as que apresentaram o menor crescimento, possivelmente devido ao baixo teor de Cobre no biofertilizante (Tabela 1).

O tempo influenciou no ganho de altura de todas as hortaliças, mas, somente para alface e tomate foram encontradas interações entre tempo e presença do biofertilizante (Tabela 2; Figuras 1A e 1B), apontando diferença nos momentos de maiores ganhos em altura entre as culturas, sendo que os maiores ganhos de alface no tratamento com o biofertilizante foram detectados nas aferições 3 e 4 e no tomate o foram nas aferições 1 e 2 . 
Figura 1 - Crescimento em altura $(\mathrm{mm})$ das hortaliças alface $(A)$ e tomate $(B)$ tratadas com (quadrados cheios) e sem biofertilizante (círculos vazios). Os pontos centrais representam a média e as medidas de dispersão representam um intervalo de confiança de $95 \%$ (IC $95 \%$ ) em torno das médias. A não sobreposição de um IC $95 \%$ de um tratamento sobre a média de qualquer outro indica diferença estatística.

A

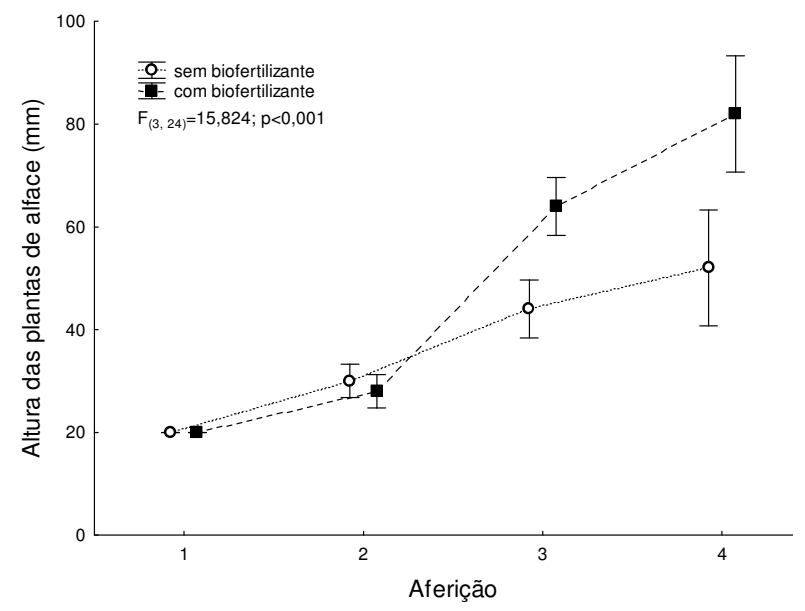

B

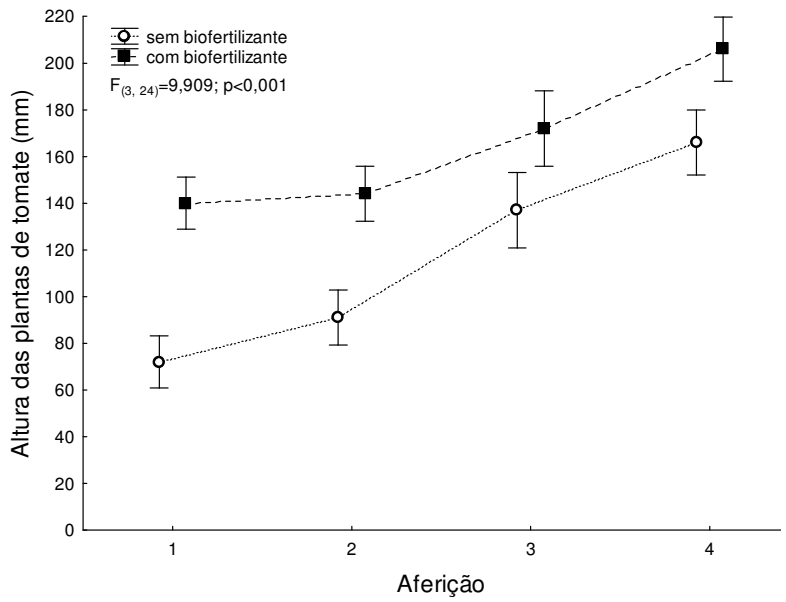

Apesar do benefício evidente do uso do biofertilizante, a sua concentração, o tipo de substrato e de hortaliça utilizados ainda precisam ser considerados para uma correta definição da quantidade a ser usada, sob a pena de obtenção de efeitos negativos como a inibição do crescimento vegetal (ZANDONADI et al., 2014). Por exemplo, o Boro apresenta estreitos intervalos que definem a sua deficiência ou a sua toxidez (GUPTA, 1983), precisando ser ministrado em doses conhecidas.

A aplicação de misturas biofertilizantes promove reconhecidos benefícios no cultivo de hortaliças como a melhoria das propriedades físicas, da acidez, da atividade biológica e do equilíbrio de micronutientes no solo (GALBIATTI et al., 1996; SEIXAS da Silva et al., 2016; ZANDONADI et al., 2014). A ação como redutores de efeitos negativos em circunstâncias não favoráveis, ou seja, de estresse também já é descrita para os biofertilizantes (HUSSAIN et al., 2002; LAMABAM et al., 2011; PANDEY et al., 2013) e implica em mais uma vantagem do seu uso. Desta forma, além do uso de boas práticas de manejo como o plantio direto, ou de adubos verdes e da redução do uso de implementos agrícolas (LOUREIRO et al., 2016), o uso de biofertilizantes também contribui para 0 desenvolvimento de uma agricultura responsável e sustentável, sendo importante opção para a manutenção da qualidade dos cultivos (BHARDWAJ et al., 2014; RIBEIRO et al., 2011). Os seus baixos custos de obtenção, através do uso de recursos locais (e.g., subprodutos agrícolas) a 
melhoria na qualidade das plantas e da estrutura física do solo, a otimização na ciclagem de nutrientes e melhoras ambientais nos sistemas de cultivo (CAVALCANTE et al., 2010; KIEHL, 2010; SOARES et al., 2014).

\section{CONCLUSÃO}

Os resultados obtidos ilustram efetivo e rápido desenvolvimento de alface, rúcula, tomate, cebolinha e repolho quando submetidas à aplicação de biofertilizante (Cresce Fácil). Esse desempenho obtido se deve aos princípios ativos presentes no biofertilizante e são resultados promissores para o desenvolvimento precoce e sustentável de hortaliças.

\section{REFERÊNCIAS}

ADAMS, P.; GRAVES, C. J.; WINSOR, G. W. Some effects of micronutrients and liming on the yield, quality and micronutrient status of lettuce grown in beds of peat. Journal of Horticultural Science, v. 61, n. 4, p. 515-521, 1986.

BETTIOL, V.; MORANDI, M. A. B. Biocontrole de doenças em plantas: Usos e perspectivas. Jaguariúna: Embrapa Meio Ambiente, 2009. 341p.

BHARDWAJ, D. et al. Biofertilizers function as key player in sustainable agriculture by improving soil fertility, plant tolerance and crop productivity. Microbial Cell Factories, v. 13, p. 66, 2014.

BRASIL. Decreto $n^{0} 4.954$ de 14 de janeiro de 2004. Aprova o Regulamento da Lei $n^{0}$ 6.894, de 16 de dezembro de 1980 que dispõe sobre a inspeção e fiscalização da produção e comércio de fertilizantes, corretivos, inoculantes ou biofertilizantes destinados à agricultura, e dá outras providências. Diário Oficial [da] República Federativa do Brasil, Poder Executivo, Brasília, DF, 15 jan. 2004. Seção 1, p. 2.

CARVALHO, J. L. N. et al. Potencial de sequestro de carbono em diferentes biomas do Brasil. Revista Brasileira de Ciência do Solo, v. 34, p. 277-289, 2010.

CAVALCANTE, L. F. et al. Água salina e esterco bovino líquido na formação de mudas de goiabeira cultivar paluma. Revista Brasileira de Fruticultura, v. 32, n. 1, p. 251-261, 2010. 
GALBIATTI, J. A. et al. Efeitos de diferentes doses e épocas de aplicação de efluente de biodigestor e da adubação mineral em feijoeiro-comum (Phaseolus vulgaris $L$.) submetido a duas lâminas de água por meio de irrigação por sulco. Científica, v. 24, n. 1, p. 63-74,1996.

GRANGEIRO, L. C. et al. Produção de rúcula em hidroponia com diferentes concentrações de cobre. Horticultura Brasileira, v. 21, n. 1, p. 69-72, 2003.

GUPTA, U. C. Boron deficiency and toxicity symptoms for several crops as related to tissue boron levels. Journal of Plant Nutrition, v. 6, p. 387-395, 1983.

HERNANI, L. C. et al. Sistemas de manejo de solo e perdas de nutrientes e matéria orgânica por erosão. Revista Brasileira de Ciência do Solo, v. 23, p.145-154, 1999.

HUSSAIN, N. et al. Effectiveness of Rhizobium under salinity stress. Asian Journal of Plant Science, v. 1, p.12-14, 2002.

KASCHUK, G. et al. Quantifying effects of different agricultural land uses on soil microbial biomass and activity in Brazilian biomes: inferences to improve soil quality. Plant Soil, v. 338, p. 467-481, 2011.

KIEHL, E. J. Fertilizantes organominerais. Piracicaba: Agronômica Ceres, 1993. 189p.

KIEHL, E. J. Novos fertilizantes orgânicos. Piracicaba: Ed. Desgaspari, 2010, 248p.

LAMABAM, P. S.; Gill, S. S.; Tuteja, N. Unraveling the role of fungal symbionts in plant abiotic stress tolerance. Plant Signal Behaviour, v. 6, p.175-191, 2011.

LOUREIRO, D. C. et al. Influência do uso do solo sobre a conservação de carbono na biomassa microbiana em sistemas orgânicos de produção. Revista Brasileira de Agroecologia, v. 1, p. 1-10, 2016.

MEDEIROS, D. C. et al. Produção de mudas de alface com biofertilizantes e substratos. Horticultura Brasileira, v. 25, p. 433-436, 2007.

NOVOTNY, V. The danger of hypertrophic status of water supply impoundments resulting from excessive nutrient loads from agricultural and other sources. Journal of Water Sustainability, v. 1, p. 1-22, 2011.

PANDEY, S. et al. Molecular characterization of Alr1105 a novel arsenate reductase of the diazotrophic cyanobacterium Anabaena sp. PCC7120 and decoding its role in abiotic stress management in Escherichia coli. Plant Molecular Biology, v. 83, p. 417-432, 2013. 
RIBEIRO, M. B. et al. Biofertilizante: valorizando estudos de tecnologias agroecológicas de produção. Cadernos de Agroecologia, v. 6, n. 2, 2011.

SEIXAS DA SILVA, S. A. et al. Uso de Biofertilizante Líquido como Estratégia de Produtividade em uma Horta Escolar Agroecológica. Cadernos de Agroecologia, v. 11, n. 2, dez. 2016. ISSN 2236-7934. Disponível em: <http://www.abaagroecologia.org.br/revistas/index.php/cad/article/view/21065>. Acesso em: 28 maio 2017.

SOARES, E. R. et al. Emergência e desenvolvimento inicial de plântulas de cupuaçu em substrato enriquecido com biofertilizante. Revista Brasileira de Agroecologia, v. 9, p. 176-184, 2014.

YURI, J. E. et al. Comportamento da alface americana em função do uso de doses e épocas de aplicação de boro em cultivo de inverno. Horticultura Brasileira, v. 22, n. 3, p. 593-596, 2004.

ZANDONADI, D. B. et al. Ação da matéria orgânica e suas frações sobre a fisiologia de hortaliças. Horticultura Brasileira, v. 32, p. 14-20, 2014. 